\begin{tabular}{|l|l|l|l|l|l|}
\hline J. Tek. Ling & Vol. 12 & No. 2 & Hal. 217 - 223 & Jakarta, Mei 2011 & ISSN 1441-318X \\
\hline
\end{tabular}

\title{
AKUNTING SUMBERDAYA ALAM LAHAN DAN LINGKUNGAN: KABUPATEN KUTAI TIMUR
}

\author{
Rony M. Bishry \\ Peneliti di Pusat Teknologi Lingkungan \\ Badan Pengkajian dan Penerapan Teknologi
}

\begin{abstract}
The natural resources utilization for economic development has become the driver of land cover and environmental change. Logging and coal production have created dry land. The policy of natural resources utilization for development in Kutai Timur Regency has changed the net value of its natural resource capital. For Kutai Timur Regency it is recorded that between the year of 2004 - 2006, the income of its natural resources was as much as Rp. 13,39 Trillion.

The total change of the economic value of its resource has also created the need for the environmental cost of Rp. 191 Billion annually since around 95,742 ha has changed into dry land. However comparing to the need of annual budget to treat the critical land, the net value of its natural resources capital is relatively high.
\end{abstract}

Key Words: Natural Resources Accounting, Natural resources management, Environmental cost

\section{PENDAHULUAN}

\subsection{Latar Belakang}

Pemerintah Daerah Kutai Timur mengambil prakarsa untuk menempuh orientasi baru dalam pengelolaan sumberdaya alam dengan penekanan pada penggunaan lahan untuk agribisnis dan tidak hanya mengandalkan sumberdaya alam yang tidak terbarukan seperti minyak dan batubara. Orientasi baru ini dilakukan agar pemanfaatan sumberdaya alam yang ada di Kabupaten Kutai Timur dapat memberikan manfaat optimal bagi pemerintah dan masyarakat, serta mampu mempertahankan kondisi lingkungan agar tidak terlalu terdegradasi.

Pemanfaatan sumberdaya alam sangat penting bagi keberlanjutan pembangunan daerah Kabupaten Kutai Timur. Telah luas diketahui bahwa Kabupaten Kutai Timur termasuk daerah yang kaya akan sumberdaya alam, terutama bahan tambang. Sektor pertambangan, yang ditopang terutama oleh minyak, gas, dan batubara, menyumbang sekitar $72,9 \%$ dari total Produk Domestik Regional Bruto. (PDRB) (PDRB) Kutai Timur tahun 2008. Kontribusi ini disusul oleh sektor pertanian sebesar $9,3 \%$, perdagangan $2,6 \%$, keuangan dan perbankan $2,2 \%$, pengangkutan dan komunikasi $2,1 \%$, jasa-jasa $1,0 \%$, industri pengolahan $0,6 \%$ dan Dengan demikian dapat dimengerti bila setiap gejolak pada sektor pertambangan akan memberikan pengaruh terhadap PDRB daerah ini. ${ }^{1)}$

Setelah langkah reorientasi 
penggunaan sumberdaya alam tersebut terwujud, langkah berikutnya adalah terkait dengan bagaimana mengelola sumberdaya alam pada tingkat yang paling menguntungkan. Kemudian, langkah selanjutnya adalah membuat profil investasi atas setiap sumberdaya alam. Reorientasi penggunaan sumberdaya alam terutama lahan paling tidak akan mendatangkan 3 manfaat. Pertama, masyarakat akan mendapat manfaat, baik manfaat langsung maupun tidak langsung. Kedua, penerimaan pemerintah daerah akan meningkat, sehingga kemampuan pemerintah daerah dalam manuver fiskal dapat ditingkatkan dalam rangka meningkatkan kesejahteraan daerah. Ketiga, terdapat jaminan bahwa pemanfaatan sumberdaya tersebut berada pada titik optimal.

Atas dasar uraian tersebut di atas, permasalahan yang harus diuraikan dalam kajian ini dapat dirumuskan sebagai berikut:

- Bagaimana distribusi spasial sumberdaya alam lahan dan konfigurasi keterkaitannya dengan kawasan pengembangan ekonomi?

- Bagaimana penggunaan sumberdaya alam lahan dapat memberi kontribusi pada pendapatan daerah?

- Bagaimana penggunaan sumberdaya alam lahan menyebabkan kerusakan lingkungan dan seberapa besar ongkos lingkungannya?

\subsection{Tujuan dan Sasaran}

Tujuan pengkajian ini adalah:

- Menganalisa dampak penggunaan sumberdaya alam dengan akunting SDA dan lingkungan terhadap nilai neto ekonomi total modal SDA dan lingkungan.

- Menganalisa penggunaan sumberdaya alam sebagai elemen inti dalam pengembangan daerah dan dampaknya terhadap pendapatan daerah dan lingkungan.
Sasaran kajian ini ingin mendapatkan ongkos lingkungan dibandingkan dengan keuntungan penggunaan sumberdaya alam untuk pengembangan ekonomi.

\section{METODOLOGI}

\subsection{Lokasi dan Waktu Kajian}

Lokasi kajian adlah Kabupaten Kutai Timur Provinsi Kalimantan Timur. Wilayah Kabupaten Kutai Timur, secara geografis, berada pada posisi $115^{\circ} 56^{\prime} 26^{\prime \prime}$ - $118^{\circ} 58^{\prime} 19^{\prime \prime}$ Bujur Timur dan 1 ${ }^{\circ} 52^{\prime} 39^{\prime \prime}$ Lintang Utara $0^{\circ} 02$ '10" Lintang Selatan. Kabupaten Kutai Timur memiliki luas $35.747,50 \mathrm{~km}^{2}$ (termasuk wilayah perairan laut) atau $17 \%$ dari luas Propinsi Kalimantan Timur, dan luas wilayah daratan adalah $31.765,91 \mathrm{~km}^{2}$. .)

Kabupaten Kutai Timur terletak pada posisi yang strategis karena berada pada jalur poros lintas Trans Kalimantan, yang semakin ramai dimanfaatkan dalam transportasi orang dan barang. Selain itu kabupaten ini merupakan pusat dari Kawasan Pengembangan Terpadu (Kapet) SASAMBA (Sangatta - Samarinda - Balikpapan) dan kawasan segitiga pertumbuhan BONSASEMAWA (Bontang - Samarinda Sebulu - Muara Wahau). Hal ini semakin diperkuat dengan posisi Kabupaten Kutai Timur yang menghadap ke arah Selat Makassar, yang merupakan jalur pelayaran nasional, regional dan internasional. ${ }^{3)}$

Kajian ini dilakukan pada tahun 2008 dengan menggunakan data tahun 2004 sampai dengan 2006.

\subsection{Kerangka Pikir}

Pada setiap penggunaan SDA sudah barang tentu akan terjadi perubahan tutupan lahan, penggunaan sumberdaya hutan yang berlebihan dan batubara menyisakan lahan kering belukar. Perubahan yang terjadi identik dengan perubahan nilai ekonomi lahan dan dampak yang menimbulkan serangkaian keadaan yang berbeda. Dampak 
penggunaan SDA yang terjadi akan diukur dalam kategori perubahan nilai ekonomi neto tutupan lahan dan perubahan lingkungan. Selain itu di sisi lain dapat terjadi dampak negatif penggunaan SDA. Perubahan lingkungan berupa degradasi lingkungan dilakukan dengan melihat berapa lahan kering yang tercipta disebabkan penggunaan SDA untuk kegiatan ekonomi.

\section{Akunting SDA}

Akunting SDA Indonesia dilakukan oleh Reppetto (1991) ${ }^{4}$ dengan data 1970an dan 1980an. Perhatian utama pada deplesi SDA sebagai depresiasi modal SDA pada perhitungan pendapatan nasional. Akunting SDA Indonesia dibagi atas hutan, minyak, dan tanah.

Reppetto menghawatirkan eksploitasi SDA mineral, hutan dan tanah yang menyebabkan erosi, merusak SDA air, menghabiskan SDA ikan dan lainnya. Pada masa itu SDA memberikan kontribusi sekitar $43 \%$ terhadap pendapatan nasional dan sekitar $83 \%$ dari pendapatan ekspor serta menyerap 55\% tenaga kerja nasional. Kontribusi SDA ternyata diikuti dengan deplesi SDA yang tidak diperhitungkan dalam pendapatan nasional.

Repetto melihat perhitungan pertumbuhan pendapatan nasional yang terlalu tinggi dibandingkan dengan kenyataan jika deplesi SDA dihitung sebagai depresiasi. Repetto melihat adanya angka deplesi yang melebihi investasi bruto yang berarti Indonesia membiayai konsumsi nasional dengan deplesi SDA.

Sejauh ini belum ada lagi penelitian lengkap akunting sumberdaya untuk Indonesia. Akunting SDA dalam penelitian ini adalah untuk menghitung nilai ekonomi neto SDA dengan rumus valuasi sebagai berikut:

$$
\begin{gathered}
T E V=(D U V+I U V+O V)+(X V+ \\
B V)
\end{gathered}
$$

DUV adalah Nilai guna SDA

IUV adalah Nilai non guna SDA

OV adalah Nilai opsi

XV adalah Nilai keberadaan

BV adalah Nilai waris

Untuk nilai guna SDA adalah sebagai berikut:

$$
R \mathbf{n}=(\mathbf{P t}-\mathbf{C t})
$$

Dimana:

$\mathbf{R n}$ adalah Nilai guna $S D A$

Pt adalah Harga pasar per unit produk SDA

Ct adalah biaya-biaya yang dikeluarkan untuk menghasilkan per unit produk SDA.

\subsection{Pengumpulan Data}

Pengumpulan data dilakukan melalui penelurusan data sekunder berupa data spasial seperti peta kawasan hutan, peta tutupan lahan hutan dan non-hutan, peta daerah tambang, citra satelit dan tabular sesuai dengan jenis-jenis data yang diuraikan di atas dari berbagai instansi di Kementerian Kehutanan, dan instansi terkait di tingkat provinsi maupun kabupaten. Berdasarkan hasil analisis data dasar/awal selanjutnya dilaksanakan pengecekan lapangan berupa pengamatan fisik dan wawancara dengan berbagai responden yang meliputi kondisi tegakan hutan, jenis-jenis pohon yang di perdagangkan, kondisi daerah tambang, dan kondisi daerah belukar.

Untuk perhitungan net rent, data yang dikumpulkan antara lain: biaya operasional pengelolaan dan pemanenan, biaya transportasi kayu dan hasil tambang, harga kayu dan hasil tambang dipasaran setempat dan data lainnya yang terkait dengan analisis fisik dan moneter sumberdaya hutan, pertambangan, dan belukar.

Dimana:

TEV : adalah Nilai ekonomi neto SDA 


\section{HASILDAN PEMBAHASAN}

\subsection{Penggunaan Sumberdaya Alam}

Penggunaan sumberdaya alam lahan akan difokuskan pada peruntukan pertanian dan perkebunan. Kerusakan hutan and pertambangan batubara telah menyisakan lahan kering. Lahan kering sebenarnya sangat potensial untuk mengembangkab pertanian lahan kering yang memiliki nilai balik finansial yang tinggi. Namun demikian lahan kering ini memerlukan dana perbaikan lingkungan untuk menjadi lahan yang bernilai ekonomis. Selanjutnya pada Tabel 1 dan Tabel 2 akan diperlihatkan Luas lahan sumberdaya alam tahun 2004 dan tahun 2006. Analisa akan dilakukan untuk perkebunan, kehutanan, pertambangan, dan rawa. Perubahan lahan terjadi terutama karena semakin luasnya daerah pertambangan dan perkebunan. ${ }^{5)}$

\subsubsection{KEHUTANAN}

Neraca fisik sumberdaya alam hutan pada bahasan ini difokuskan pada kawasan budidaya kehutanan, yaitu hutan produksi yang terdiri dari hutan produksi terbatas (HPT) dan hutan produksi tetap (HP). Hal ini karena pada kawasan tersebut terdapat potensi sumberdaya alam hutan berupa kayu dan potensi lahan untuk memproduksi sumberdaya hutan yang menjadi sumber pendapatan bagi pembangunan daerah khususnya dan nasional umumnya. Perhitungan meliputi neraca perubahan luasan kawasan berhutan dan potensi kayu pada areal berhutan yang terdapat di kawasan tersebut.

\section{Neraca Fisik Berdasarkan Luas pada Hutan Produksi Terbatas}

Luas kawasan Hutan Produksi Terbatas (HPT) berdasarkan peta kawasan hutan adalah $791.292 \mathrm{Ha}$. Berdasarkan penutupan lahannya pada tahun 2004, HPT terdiri dari 190.370 ha hutan primer lahan kering, hutan kering bekas tebangan $348.725 \mathrm{Ha}$, hutan tanaman 2.202 $\mathrm{Ha}$, dan non hutan seluas 249.994,89 Ha. Pada areal non hutan tersebut terdapat belukar seluas $236.667 \mathrm{Ha}^{4)}$

Sedangkan tutupan lahan pada tahun 2006 pada areal berhutan terdiri dari 4 ha hutan rawa/gambut, $170.626 \mathrm{Ha}$ hutan primer lahan kering, 344.615 Ha hutan kering sekunder, $33.649 \mathrm{Ha}$ hutan tanaman. Pada areal non hutan terdapat $242.178 \mathrm{Ha}$ belukar. ${ }^{5)}$

Secara lebih rinci perubahan penutupan Iahan pada Kawasan Hutan Produksi Terbatas dapat dilihat pada Tabel 1 di bawah.

Tabel 1. Neraca Fisik Luas Hutan ProduksiTerbatas (Ha)

\begin{tabular}{|l|l|r|l|r|}
\hline No & Tutupan & \multicolumn{1}{|l|}{$\mathbf{2 0 0 4}$} & $\mathbf{2 0 0 6}$ & Perubah \\
\hline 1 & Hutan primer & $190,370.0$ & $170,630.0$ & $(19,740.0)$ \\
\hline 2 & Hutan eks Teb. & $348,725.0$ & $344,614.9$ & $(4,110.1)$ \\
\hline 3 & Hutan Tanam & $2,202.0$ & $33,649.0$ & $31,447.0$ \\
\hline 4 & Belukar & $236,667.9$ & $242,398.0$ & $5,730.1$ \\
\hline & Total & $777,964.9$ & $791,291.9$ & $13,327.0$ \\
\hline
\end{tabular}

Sumber: PTISDA-BPPT (2008)

Berdasarkan perbandingan penutupan lahan antara tahun 2004 dan 2006 diketahui terjadi perubahan penutupan lahan pada Kawasan Hutan Produksi Terbatas. Perubahan tersebut yaitu pada hutan kering primer terjadi penurunan sebesar 19.744 ha dan hutan kering bekas tebangan terjadi penurunan sebesar 4.110 ha. Penurunan ini ditenggarai akibat adanya penebangan liar (llegal logging), sehingga menjadi kawasan hutan tersebut berubah menjadi kawasan belukar, hal ini ditunjukkan dengan adanya peningkatan pada luasan belukar pada areal non hutan yaitu sekitar $5.730 \mathrm{Ha}$. Perinciannya adalah dengan luas areal 
non hutan tahun 2004 seluas 236,667 Ha, menjadi seluas 242.398 Ha pada tahun 2006, atau menurun sebesar 5.730.11 $\mathrm{Ha}$.

\section{Neraca Fisik Berdasarkan Luas Pada Hutan Produksi Tetap}

Luas Hutan Produksi Tetap berdasarkan peta kawasan adalah 954.177 ha. Berdasarkan penutupan lahannya pada tahun 2004 areal berhutan terdiri dari 33,012 ha hutan primer, $\mathbf{3 1 2 , 5 1 4}$ ha hutan sekunder, 189,937 ha hutan tanaman dan areal non hutan belukar sebesar $522,023 \mathrm{Ha}$. Sedangkan penutupan lahan pada tahun 2006, areal hutan terdiri dari $2.204 \mathrm{Ha}$ hutan primer, 281,485 Ha hutan sekunder, 42,474 Ha hutan tanaman dan areal non hutan belukar sebesar 460,551 Ha.

Berdasarkan perbandingan penutupan lahan antara tahun 2004 dan 2006 diketahui terjadi perubahan tutupan lahan pada areal non hutan luas belukar menurun secara net sebesar $100.508 \mathrm{Ha}$. Penurunan luas areal belukar diakibatkan oleh kegiatan Penanaman hutan industri meskipun ada tambahan dari penebangan liar, perambahan perladangan, dan tumpang tindih dengan kegiatan sektor lain seperti perkebunan dan pertambangan.

Secara lebih rinci perubahan penutupan lahan pada Kawasan Hutan Produksi Tetap dapat dilihat pada Tabel 2 di bawah.

Tabel 2. Neraca Fisik Luas Hutan ProduksiTetap $(\mathrm{Ha})$

\begin{tabular}{|l|l|l|l|l|}
\hline No & Tutupan & $\mathbf{2 0 0 4}$ & $\mathbf{2 0 0 6}$ & Perubah \\
\hline 1 & Hutan primer & 33,012 & 22,204 & $(10,808)$ \\
\hline 2 & Hutan eks Teb. & 312,514 & 281,485 & $(31,029)$ \\
\hline 3 & Hutan Tanam & 42,474 & 189,937 & 147,463 \\
\hline 4 & Belukar & 522,023 & 419,666 & $(101,472)$ \\
\hline & Total & 910,023 & 954,177 & 44,154 \\
\hline
\end{tabular}

Sumber: PTISDA-BPPT (2008)
Secara neto, telah terjadi penurunan belukar sebesar 95,742 ha. Peningkatan belukar di hutan primer dan bekas hutan telah sebesar 62 ribu ha terkurangi dengan adanya peningkatan hutan tanaman sebesar hampir 179 ribu ha.

\section{Neraca Fisik dan Moneter Hutan Produksi (HPT dan HPT)}

Setelah neraca fisik hutan produksi berdasarkan luasan penutupan lahan yang kemudian diperoleh neraca fisik hutan produksi berdasarkan potensi kayu dan nilai moneternya maka berdasarkan konsep Natural Resources Accounting untuk melihat perubahannya atas waktu dan harga dapat dilihat pada tabel di bawah. Nilai economic rent pada neraca moneter perubahannya sangat dipengaruhi jumlah potensi dan tingkat harga kayu.

Harga kayu pada tahun 2004 harga kayu adalah USD 62,22 dan tahun 2006 USD 100. Dengan mempertimbangkan biaya operasi dan transportasi, net rent kayu adalah sebesar USD 36,00 Pada tahun 2004 dan USD 51,50 pada tyahun 2006. Mempertimbangkan Nilai economic rent stok awal sumberdaya alam Hutan Produksi pada tahun 2004 adalah sebesar USD 1.517.705.881,4 dan Nilai economic Rent stok awal tahun 2006 adalah sebesar USD 2.184.893.002,5. Dengan demikian nilai perubahan selama dua tahun sebesar USD 9.191.291,2 atau sekitar 90 Miliar Rupiah. Artinya terjadi peningkatan pendapatan dari kayu sebesar (90 Miliar Rupiah). ${ }^{6)}$

\subsubsection{PERTAMBANGAN}

Kabupaten Kutai Timur memiliki potensi batubara yang cukup besar dengan kualitas yang baik. Potensi batubara Kutai Timur sangat dominan di Kalimantan Timur adalah sanga tersebar hampir di seluruh area kabupaten. Batubara sangat dominan, sehingga untuk perhitungan ekonomi pertambangan digunakan nilai ekonomi 
batubara.

Pola penyebaran batubara di KTimur menyebar pada batuan yang terbentuk pada zaman Kenozoikum (Eosen-Pleistosen) terdiri atas Formasi Tanjung, Berai, Warukin, Dahor yang merupakan batuan sedimen yang mendominasi hamparan berbentuk perbukitan.

Penambangan terus dilakukan dengan orientasi keperluan ekspor sehingga menjadi sumber penerimaan pusat dan daerah. Namun demikian pasca penambangan banyak meninggalkan lahan lingkungan yang tidak sebaik sebelum penambangan. Disamping itu pula kegiatan merusak sarana seperti infrastruktur transportasi.

Dari data tutupan Iahan untuk pertambangan batubara di Kutai Timur adalah seluas lebih dari 600 ribu ha pada tahun 2008 . Dari keseluruhan tutupan lahan batubara ini Perusahaan terbesar KPC beroperasi di lahan seluas lebih dari 100 ribu Ha. Cadangan di Kutim keseluruhan adalah 1,824,986,260 Ton di bandingkan dengan total cadangan keseluruhan Provinsi Kaltim sebesar 4,066,962,260 Ton. Dengan demikian terjadi kegiatan pertambangan yang sangat besar di Kabupaten Kutai Timur. ${ }^{7)}$

Dari periode tahun 2004-2006, telah diproduksi sekitar 48,7 juta ton untuk 2 tahun. Harga Batubara per to US\$ 55 dengan net rent US\$ 32 per ton setelah dikurangi biaya produksi dan transportas. Total net rent yang diterima adalah sebesar US\$ 1,56 Milyar atau Rp. 14 Triliun.

Luas kawasan pertambangan berarti ada potensi deplesi sumberdaya alam pertambangan dan meluasnya kawasan pasca tambang yang rusak secara lingkungan. Kerusakan lingkungan berarti ada potensi penambahan lahan kering/ belukar sebesar 600 ribu ha.

\subsubsection{Sumberdaya Lahan Belukar}

Lahan belukar pada tahun 2004 adalah $236,667.9 \mathrm{Ha}$ untuk hutan produksi terbatas dan 522,023 Ha untuk hutan produksi tetap, total belukar adalah $758,690.9 \mathrm{Ha}$. Lahan belukar pada tahun 2006 adalah 242,398.0 Ha untuk hutan produksi terbatas dan 419,666 Ha untuk hutan produksi tetap, total belukar adalah 661,064.0 Ha. Penurunan belukar adalah 95,742. Penurunan ini disebabkan oleh penanaman hutan tanaman seluas 178,910 ha. Namun demikian penurunan hanya lebih kecil dari luas penanaman karena adanya deplesi lahan seluas $82,178 \mathrm{Ha}$ disebabkan oleh kegiatan pertambangan dan pengambilan kayu di hutan. Deplesi hutan karena pengambilan kayu adalah seluas $65,687 \mathrm{Ha}$. Sisa deplesi seluas 16,391 Ha dapat disimpulkan akibat dari kegiatan pertambangan batubara.

\subsection{Perubahan Nilai SDA dan Lingkungan}

Nilai ekonomi hutan adalah nilai ekonomi total sumberdaya alam hutan yang meliputi nilai guna (use value) dan bukan guna (non use value). Nilai ekonomi total hutan yang dijadikan dasar perhitungan adalah nilai ekonomi total hutan hasil kajian Natural Resources Management (NRM) (2002). Nilai ekonomi total hutan adalah sebesar Rp. 38.399.400,- per ha/th, yang terdiri dari Rp.20.118.920,- untuk nilai guna langsung, Rp. 16.522.460,- dari nilai guna tidak langsung, dan Rp. 1.758.020,- untuk nilai opsi. Dengan adanya Perubahan (-) 65,687 ha maka ada penurunan nilai ekonomi SDA sebesar Rp. 4,49 Triliun

Berdasarkan hasil studi Junaidi (2005), 8) nilai ekonomi perkebunan kelapa sawit per ha selama 25 tahun dengan discount rate $10 \%$ adalah sebesar $\mathrm{Rp}$. 540.851.281,atau $\mathrm{Rp} 21.634 .051,-$ per tahun. Dengan adanya Perubahan (+) 178.910 ha maka ada peningkatan nilai ekonomi SDA sebesar Rp. 3,87 Triliun.

Nilai ekonomi batubara, diperoleh dengan mencari nilai sewa bersih (net rent) per ton batubara. Nilai tersebut diperoleh dari selisih harga FOB batubara dikurangi biaya ekstraksi, pengolahan, transportasi 
dan normal profit. Dengan analisis tersebut diperoleh nilai net rent per ton batubara adalah US\$ 32 per ton untuk tahun 2004 2006. Dari periode tahun 2004-2006, telah diprduksi sekitar 48,7 juta ton untuk 2 tahun. Total net rent yang diterima adalah sebesar US\$ 1,56 Milyar. Atau Rp. 14 Triliun.

Total perubahan nilai ekonomi SDA Kutai Timur adalah:

(-) Rp. 4,49 Triliun + Rp. 3,87 Triliun + 14 triliun +90 Milyar) $=13.39$ Triliun

Disamping itu, ada sekitar 95,742 ha dari keseluruhan perubahan tutupan lahan Kutai Timur adalah lahan kritis belukar. Dari segi biaya kerusakan, diperlukan dana sebesar minimal Rp 6 juta untuk penanaman dan pemeliharaan pohon (kopi, coklat atau jarak pagar) selama 3 tahun pertama atau Rp 2 juta per tahun. Setelah pohon berusia 3 tahun, lahan dapat dianggap tidak kritis lagi. Untuk itu diperlukan dana sebesar Rp 2 juta $X 95,742$ ) ha= RP. 191,- milyar/tahun untuk penanganan lahan kritis belukar.

Dengan membandingkan total perubahan nilai ekonomi SDA sebesar Rp. 13,39 Triliun untuk 2 tahun dan dengan keperluan dana per tahun untuk penanganan lahan kritis sebesar RP. 191,-- milyar/tahun, perubahan neto nilai modal SDA Kutai Timur sangat besar sekali.

\section{KESIMPULAN DAN SARAN}

Penggunaan Sumberdaya alam telah merubah tutupan lahan. Perubahan terjadi dengan semakin luasnya daerah pertambangan dan Pengambilan kayu dan penggunaan lahan untuk pertambangan sebagian besar mengakibatkan perubahan tutupan lahan hutan dan lahan tambang menjadi belukar dan lahan kritis.

Total perubahan nilai ekonomi SDA Kabupaten Kutai Timur dari tahun 2004 ke tahun 2006 adalah sebesar Rp. 13,39 triliun. Namun demikian ada sekitar 95,742 ha adalah lahan kritis belukar. Dari segi biaya kerusakan, diperlukan dana untuk perbaikan lahan kritis sebesar RP. 191,-- milyar/tahun.

Dengan membandingkan total perubahan nilai ekonomi SDA sebesar dengan keperluan dana untuk perbaikan lahan kritis, perubahan neto nilai modal SDA relatif sangat besar.

Disarankan pemerintah daerah tidak hanya melihat peranan keuntungan penggunaan sumberdaya alam dalam pengembangan ekonomi tapi juga ongkos lingkungan yang timbul dari penggunaan sumberdaya alam ini.

\section{DAFTAR PUSTAKA}

1. Biro Pusat Statistik, 2009, Kabupaten Kutai Timur dalam Angka..

2. Pemerintah Kabupaten Kutai Timur (2008), Sekilas Kabupaten Kutai Timur

3. BAPPEDA Kabupaten Kutai Timur, 2008, Rencana Strategis Kabupaten Kutai Timur.

4. Repetto, et.al., 1989, Wasting Assets: Natural Resources in the National Income Accounts, World Resources Institute.

5. Pusat Teknologi Inventarisasi Sumberdaya Alam - PTISDA BPPT, 2008, Laporan Akunting Sumberdaya Alam Kabupaten Kutai Timur.

6. Natural Resources Management, 2002, Presentase Nilai dan Jasa Hutan, 2003.

7. Dinas Pertambangan Kabupaten Kutai Timur, 2008, Renstra Pertambangan Kabupaten Kutai Timur,

8. Junaidi, 2005, Nilai Ekonomi Perkebunan Kelapa Sawit, Thesis, Program Pascasarjana Lingkungan, Universitas Indonesia. 